\title{
Evaluation of the thermal behaviour of bevelled cutting inserts using a numerical approach
}

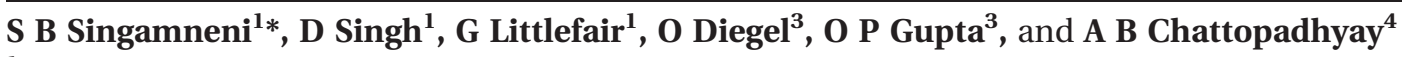 \\ ${ }^{1}$ Centre for Advanced Manufacturing Technology, AUT University, New Zealand \\ ${ }^{2}$ Creative Industries Research Institute, AUT University, New Zealand \\ ${ }^{3}$ Department of Mechanical Engineering, Indian Institute of Technology, Delhi, India \\ ${ }^{4}$ Department of Mechanical Engineering, Indian Institute of Technology, Kharagpur, India
}

The manuscript was received on 1 December 2006 and was accepted after revision for publication on 1 August 2007.

DOI: 10.1243/09544054JEM799

\begin{abstract}
The nose geometry of a hard and brittle metal cutting tool is generally modified in order to avoid the premature failure due to fracture under tensile stresses. While most research findings point to a favourable mechanical load pattern, the possible influence of the shape of the geometry on the thermal fields and the consequent changes in the stressed state of the tool seem to have attained less attention. The present work aims at establishing the thermal behaviour of bevelled tools under varying geometrical and process parameters. Data generated from statistically designed experiments and quick-stop chip samples are coupled to conduct numerical investigations using a mixed finite and boundary element solution to obtain the temperature distribution in bevelled carbide inserts. Due consideration is given to the presence of the stagnation zone and its size and shape. While the cutting forces and temperatures increased owing to the blunt shape of the tool, the possible absence of tensile stresses was found to be the likely effect of a more uniform temperature distribution resulting from a significant plastic contact on the principal flank and the consequent flank heat source. The characteristic low-temperature zones close to the nose of the conventional tool are taken over by the stagnation zone in bevelled tools.
\end{abstract}

Keywords: bevelled tools, stagnation zone, thermal fields, numerical methods

\section{INTRODUCTION}

While the early stages of research in metal cutting were mostly aimed at developing new cutting tool materials or improving the properties of existing materials, since the early 1960s geometrical modifications have gained importance as a promising means to improve cutting efficiency. Restricting the contact length [1-3], edge rounding or chamfering $[\mathbf{4}, \mathbf{5}]$, and the application of double rake geometry $[6,7]$ have been some of the most commonly investigated modifications.

Chao and Trigger [1], Bhatacharya and Ghosh [2], and Trigger and Bhatacharya [3] attempted to derive benefits such as reduced frictional force and rake face temperatures by restricting the chip-tool contact

${ }^{*}$ Corresponding author: Mechanical and Production Engineering, AUT University, 24 St Paul Street, Auckland, New Zealand. email: sarat.singamneni@aut.ac.nz length. The geometrical modification essentially involved cutting off a certain portion of the tool, close to the zone of chip separation. Restricting the contact length to one-third of the natural contact length was found to reduce the cutting forces and rake face temperatures as well as increase the tool life. This worked well with high-speed steel (HSS) tools while machining at relatively low cutting speeds; however, cutting tools made of brittle materials could fail prematurely owing to edge chipping or cracking when the cutting edges were sharp [8]. Also, a tool with a smaller wedge angle and with the tool wedge less closely aligned with the cutting direction would experience larger tensile stresses for the same cutting loads and hence would tend to have a lower resistance to fracture [9].

As a result, geometrical modifications such as edge rounding and chamfering were attempted for cutting tools made of brittle materials such as carbides, 
notwithstanding the fact that such geometries would raise the cutting forces and temperatures. From the results of experiments conducted with chamfered tools, Hirao et al. [4] reported a change in the mechanism of chip formation, signified by the presence of stagnant work material under the chamfered edge. A compressive type of loading was observed, with a reduction in the edge chipping and cracking.

The numerical analysis of metal cutting with chamfered and blunt tools by Movahhedy et al. [5] also showed a trapped material zone under the chamfer, which was found to act as the effective cutting edge. While the cutting forces and temperatures were reported to have increased, the chip formation process remained almost unaffected, owing to the continuous presence of the stagnation zone, which played the part of the missing sharp cutting edge.

The conventional negative rake cutting employed in the case of brittle tools, although effective in circumventing premature failure, resulted in higher cutting forces. If the concept of controlled contact cutting is attempted using such tools, a double rake geometry of the type shown in Fig. 1 results. The characteristic negative land width is sufficiently high and forms a significant portion of the chip-tool contact length. The mechanism and mechanics of chip formation would be greatly influenced by the geometrical and process parameters as reported in references [6] and [7]. While the mechanism of cutting with such tools was shown to be signified by the presence of a stable stagnation zone [7], the geometrical parameters could be optimized for improved efficiency of cutting, at different levels of the process parameters [6].

Essentially, all these geometrical modifications aim at reducing the chances of edge chipping and microcracking by converting the chip load into a largely compressive type of force distribution, but this is at the cost of increased cutting forces. It may appear to be reasonable to expect a largely compressive type of stressing in the tools, when considering the pure mechanical load acting alone on a tool with a wide

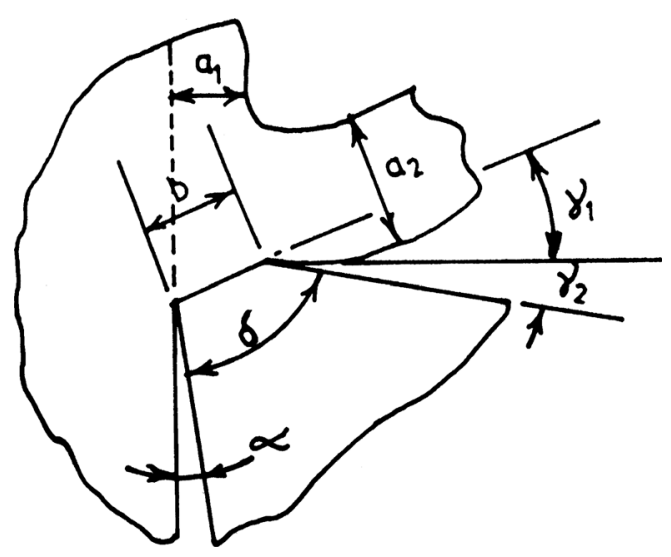

Fig. 1 The bevelled tool nose, with the load oriented in the direction of the wedge [9]. However, there is a thermal component which contributes significantly to the stressed state of a tool. The finite element analysis conducted by Ostafiev and Noschenko [10] clarified that the mechanical stresses, although dominating, would not fit into the fracturing zones of the cutting tools unless the thermal effects were considered. Consequently, the possible influence of the double rake geometry on the thermal fields would become important, and it would be premature to claim any major benefits, unless the thermal behaviour of such tools was established.

The present work aims at establishing the influence of the double rake geometry shown in Fig. 1 on the temperature distribution. While solving the thermal fields is a complex problem, even in the case of conventional cutting, the possible variation in the mechanism of chip formation resulting from the geometrical variations can add further complications. All these complications were resolved and the temperature distributions in cutting tools of varying geometries were obtained using a numerical procedure reported elsewhere [11]. The results show that the double rake geometry can avoid the adverse effects, if any, of the thermal load, by means of eliminating the characteristic zone of relatively low temperatures near the tool nose.

\section{EXPERIMENTAL DATA}

Experiments were conducted by machining steel rods with carbide cutting inserts of varying geometries. The ranges of geometrical and process parameters are listed in Table 1. The cutting tool used was carbide, SPUN 120308, P30, by Sandvik, and the work material was carbon steel $(\mathrm{C}-0.25 \%, \mathrm{Mn}-0.73 \%, \mathrm{Si}-0.05 \%$, $\mathrm{S}-0.02 \%, \mathrm{P}-0.03 \%)$.

Some significant observations made from an analysis of the results of the experimental investigations on the mechanism and mechanics of chip formation with bevelled tools are highlighted in the following sections, as they form the basis of the numerical strategies and solutions presented in this paper.

Table 1 Levels of the factors

\begin{tabular}{lrrrrr}
\hline & \multicolumn{5}{c}{ Levels } \\
\cline { 2 - 6 } & -2.378 & -1.0 & 0.0 & +1.0 & +2.378 \\
Factors & 0.2 & 0.3 & 0.4 & 0.54 & 0.81 \\
Land width, $b(\mathrm{~mm})$ & 10.0 & 15.0 & 20.0 & 27.0 & 40.0 \\
Land angle, $\gamma_{1}(\mathrm{deg})$ & 75.0 & 80.0 & 84.0 & 89.0 & 95.0 \\
Wedge angle, $\delta(\mathrm{deg})$ & 90.0 & 121.0 & 150.0 & 186.0 & 250.0 \\
Cutting speed, $V_{\mathrm{c}}(\mathrm{m} / \mathrm{min})$ & 0.1 & 0.14 & 0.16 & 0.2 & 0.26 \\
Feed, $S_{0}(\mathrm{~mm} / \mathrm{rev})$ & 1.5 & 1.95 & 2.3 & 2.75 & 3.5 \\
Depth of cut, $t(\mathrm{~mm})$ & & & & & \\
\hline
\end{tabular}




\subsection{Mathematical models}

Mathematical models were developed to establish the complex influence of the geometrical and process parameters on the principal metal-cutting responses from the data generated by statistically designed experiments. Three geometrical parameters, land width $(b)$, land angle $\left(\gamma_{1}\right)$, and wedge angle $(\delta)$, and three process parameters, cutting speed $\left(V_{\mathrm{c}}\right)$, feed $\left(S_{0}\right)$ and depth of cut $(t)$, were considered as controllable factors, the levels of which are presented in Table 1. A second-order model with logarithmic transformation was chosen, the general form of which was

$$
\begin{aligned}
Y= & b_{0}+b_{1} X_{1}+b_{2} X_{2}+\cdots+b_{11} X_{1}^{2}+b_{22} X_{2}^{2} \\
& +\cdots+b_{12} X_{1} X_{2}+b_{13} X_{1} X_{3}+\cdots
\end{aligned}
$$

where

$Y=\log _{\mathrm{e}}$ (response)

$b_{0}, b_{1}, b_{2}, \ldots$ are the regression coefficients

$X_{1}, X_{2}, X_{3}$ are the levels of factors in logarithmic form.

A $2^{6-1}$ fractional factorial rotatable central composite design was chosen. Rotatable designs ensure that the estimated response has a constant variance at all points that are the same distance from the centre of the design $[12,13]$. The experimental errors estimated from trials repeated at central points could be used to assess errors at points equidistant from the centre of the design. If, in addition to the $2^{k}$ trials, further $2 k+1$ trials are conducted, where $k$ is the number of factors, the experimental design becomes composite. The design becomes central composite when these additional trials are conducted based on the extended levels of factors equidistant from the central points, as represented by the -2.378 and +2.378 columns in Table $1[\mathbf{1 4}]$. The design facilitated the independent estimation of the first-order interaction coefficients with the assumption that third-order interactions are absent. Table 2 lists the regression coefficients for three responses, namely feed force $\left(P_{X}\right)$, principal cutting force $\left(P_{Z}\right)$, and chip contact length (CCL). The responses were the result of a combined action of the controlled contact cutting and negative rake cutting effects [6]. The optimum land geometry was found to change with varying speed-feed combinations. These models have been used in the current research to generate the cutting force and CCL data for the tools under investigation.

\subsection{Mechanism of chip formation}

Frozen chip samples were obtained using a quickstop device while machining with carbide inserts of varying geometries. A $12 \mathrm{HP}$, rigid Cincinnati shaping machine was used at a relatively low cutting speed of $80 \mathrm{~m} / \mathrm{min}$. Photomicrographs obtained using both optical microscope and scanning electron microscope (SEM) clearly demonstrate the presence

\begin{tabular}{|c|c|c|c|}
\hline Coefficients & $P_{X}$ & $P_{Z}$ & CCL \\
\hline$b_{0}$ & 4.2227 & 4.7319 & 6.5940 \\
\hline$b_{1}(b)$ & $0.0842^{*}$ & $0.0266^{*}$ & $-0.0648^{*}$ \\
\hline$b_{2}\left(\gamma_{1}\right)$ & $0.0789 *$ & $0.0190^{*}$ & -0.0089 \\
\hline$b_{3}(d)$ & $0.1168^{*}$ & $0.0438^{*}$ & 0.1681 \\
\hline$b_{4}\left(V_{\mathrm{c}}\right)$ & $-0.0364^{*}$ & $-0.0302^{*}$ & $-0.0709^{*}$ \\
\hline$b_{5}\left(S_{0}\right)$ & $0.0890^{*}$ & $0.1311^{*}$ & $0.1834^{*}$ \\
\hline$b_{6}(t)$ & $0.1578^{*}$ & $0.1535^{*}$ & -0.0131 \\
\hline$b_{12}\left(b \gamma_{1}\right)$ & $0.0304^{*}$ & 0.0026 & $-0.0259 *$ \\
\hline$b_{13}\left(b_{d}\right)$ & $-0.0396^{*}$ & $-0.0166^{*}$ & 0.0098 \\
\hline$b_{14}\left(b V_{c}\right)$ & -0.0066 & -0.0021 & 0.0206 \\
\hline$b_{15}\left(b S_{0}\right)$ & $-0.0293^{*}$ & $-0.0156^{*}$ & 0.0104 \\
\hline$b_{16}(b t)$ & -0.0087 & $-0.0064^{*}$ & $0.0216^{*}$ \\
\hline$b_{23}\left(\gamma_{1} d\right)$ & $-0.0431^{*}$ & $-0.0097 *$ & -0.0125 \\
\hline$b_{24}\left(\gamma_{1} V_{\mathrm{c}}\right)$ & $0.0277^{*}$ & $0.0075^{*}$ & 0.0073 \\
\hline$b_{25}\left(\gamma_{1} \mathrm{~S}_{0}\right)$ & 0.0032 & -0.0033 & 0.0068 \\
\hline$b_{26}\left(\gamma_{1} t\right)$ & $-0.0130^{*}$ & $-0.0081^{*}$ & 0.0058 \\
\hline$b_{34}\left(d V_{\mathrm{c}}\right)$ & $-0.0334^{*}$ & $-0.0139 *$ & 0.0114 \\
\hline$b_{35}\left(d S_{0}\right)$ & $0.0175^{*}$ & 0.0109* & $0.0275^{*}$ \\
\hline$b_{36}(d t)$ & -0.0005 & -0.0031 & 0.0210 \\
\hline$b_{45}\left(V_{\mathrm{c}} S_{0}\right)$ & 0.0133* & 0.0085* & -0.0047 \\
\hline$b_{46}\left(V_{\mathrm{c}} t\right)$ & -0.0016 & -0.0040 & $0.0345^{*}$ \\
\hline$b_{56}\left(S_{0} t\right)$ & 0.0060 & 0.0001 & -0.0085 \\
\hline$b_{11}\left(b^{2}\right)$ & $0.0312^{*}$ & $0.0187^{*}$ & $0.0367^{*}$ \\
\hline$b_{22}\left(\gamma_{1}^{2}\right)$ & $0.0171^{*}$ & $0.0101^{*}$ & $0.0460^{*}$ \\
\hline$b_{33}\left(\delta^{2}\right)$ & $0.0114^{*}$ & $0.0055^{*}$ & 0.0043 \\
\hline$b_{44}\left(V_{\mathrm{c}}^{2}\right)$ & 0.0010 & $0.0075^{*}$ & $-0.0412^{*}$ \\
\hline$b_{55}\left(S_{0}^{2}\right)$ & $0.0285^{*}$ & $0.0229^{*}$ & -0.0149 \\
\hline$b_{66}\left(t^{2}\right)$ & $0.0087^{*}$ & 0.0024 & $0.0252^{*}$ \\
\hline
\end{tabular}

Table 2 Regression coefficients

*Significant at 95 per cent confidence level.

and stability of the stagnation zone [7]. Microhardness measurements revealed that the stagnant material would have the highest hardness, owing to the accumulation of pearlite, as soft ferrite is squeezed out of the zone of the trapped material.

Figure 2 shows photomicrographs of frozen chip samples obtained while cutting with two different geometries at two different feeds. It is obvious that the shape and behaviour of the stagnated work material depends on the geometrical and process parameters. Nevertheless, it appears from Fig. 2 that the shape of the stagnation zone almost assumes that of the missing portion of the cutting edge under the bevel, with a significant amount of edge rounding, and for all practical purposes it acts as the extended portion of the cutting tool nose. Movahhedy et al. [5] also arrived at a similar conclusion, while numerically experimenting with cutting tools of a similar edge geometry, though with a relatively smaller land width. The results of such microscopic observations have led to the understanding that the presence of the stagnation zone could be simulated by assuming a triangularshaped hard material, attached to the land of the bevelled tool, while solving the thermal problem.

\section{THE NUMERICAL SOLUTION}

A numerical solution using both finite and boundary element techniques was developed to evaluate the 


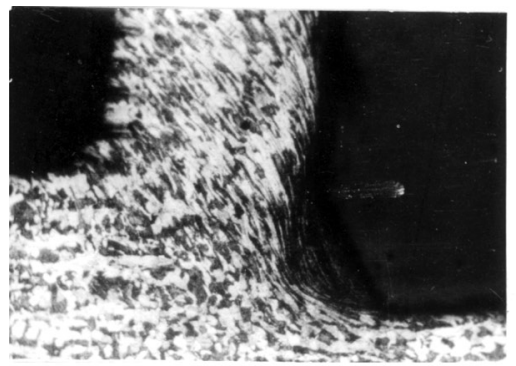

(a) $b=0.54 \mathrm{~mm}, g_{1}=27^{0}, S_{0}=0.20 \mathrm{~mm}$

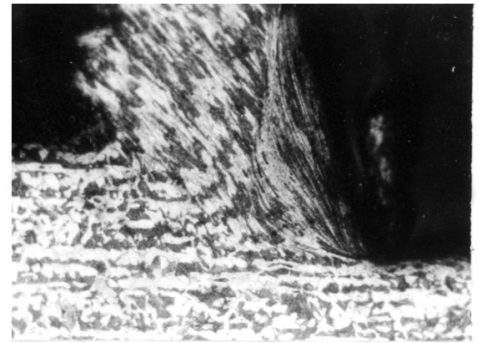

(b) $b=0.30 \mathrm{~mm}, g_{1}=27^{0}, S_{o}=0.30 \mathrm{~mm}$

Fig. 2 Photomicrographs of frozen chip samples

thermal fields in metal cutting tools. The workpiece and the chip were considered together as one domain, with the flow velocities considered in the respective fields in terms of a material flow option. Assuming a single shear plane, the primary, secondary, and wear land heat sources were evaluated, and with an appropriate distribution of these sources of heat, the chip-tool domain was analysed using the finite element method. The fixed cutting insert, discretized with triangular surface elements, was on the other hand considered as another domain and analysed using the boundary element method. The steady state heat balance was obtained by adjusting the heat flow between the two boundaries through multiple iterations. The results of these investigations, carried out largely on sharp tools and reported elsewhere [11], have shown a considerable amount of agreement with the previously published data as well as the fracture modes of metal cutting tools. The same procedure is applied to analyse the thermal fields of bevelled tools, with due consideration given to the possible changes in the geometry and rake face load distribution.

\subsection{Stagnation zone and mesh configurations}

The auxiliary chips, or silver white chips, first reported by Usui et al. [15], were observed while machining using almost all of the bevelled tools in the present investigation. Sometimes they were found sticking to the side faces of the chips, but at other times they came out separately and distinctly, and fell apart intermittently. Although the stagnated work material comes out almost continuously in the lateral direction, in the form of an auxiliary chip, fresh material always comes in to fill the gap, thus leaving a continuous zone of trapped material [16]. Hence, the presence of stagnated work material ahead of the landnot stable but continuous-becomes inevitable, and the distribution of the rake face load alters considerably. More importantly, the tool nose would be saved from the immediate vicinity of the heat sources for the majority of the contact zone, and the heat would actually have to flow into the tool by conduction through the stagnation zone. This clearly shows that due consideration of the presence of the stagnation zone is inevitable, when temperature distribution in bevelled tools is evaluated.

The presence of the stagnation zone is simulated in the current investigation by considering it as a wedgeshaped material resting on the land. The size, shape, and orientation of the stagnation zone might vary to a considerable extent with varying geometrical and process parameters, and the stagnant material flows out in the lateral direction intermittently. Nevertheless, considering the difficulties in generating such data, the shape of the stagnation zone is approximated as the zone bounded by the negative land, the newly generated work surface, and the extended primary rake surface, neglecting the lateral flow and considering the material properties as similar to that of the cutting tool. Figure 3 shows the boundary element mesh used to analyse the bevelled tools. A closer look at the tool nose area clearly shows the stagnated work material considered as an integral part of the tool nose. With double nodes employed at all the edge points, and representing corners by three nodes each in order to resolve geometrical singularities [17], the total number of nodes and elements is 305 and 408 respectively. External collocation points, placed at $0.2 \mathrm{~mm}$ from the actual nodes, have been used at those multi-node points, with matching temperature boundary conditions. The finite element grid in the work-chip domain, shown in Fig. 4, is formed such that the nodal points at the chip-tool and the work-tool contact areas would occupy the same positions in both domains, so as to enable the iterative estimation of the heat balance [11].

\subsection{Load boundary conditions}

The magnitude and distribution of the frictional forces involved in a cutting process largely influence the temperature distribution over the rake face. In a bevelled tool, the stagnated work material increases the contact zone on the principal flank. That part of the stagnation zone which is in contact with the moving work surface is subjected to a considerable 


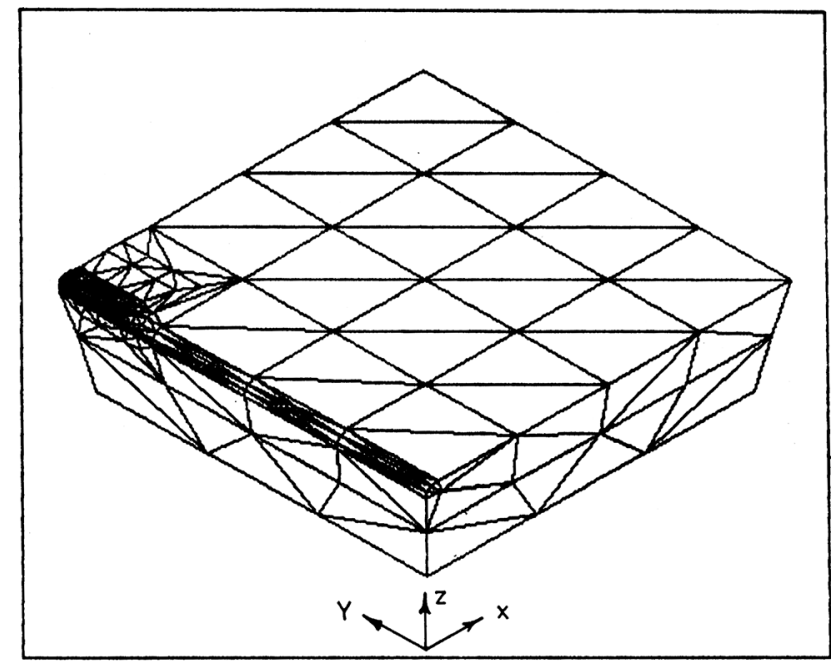

(a) Overall view

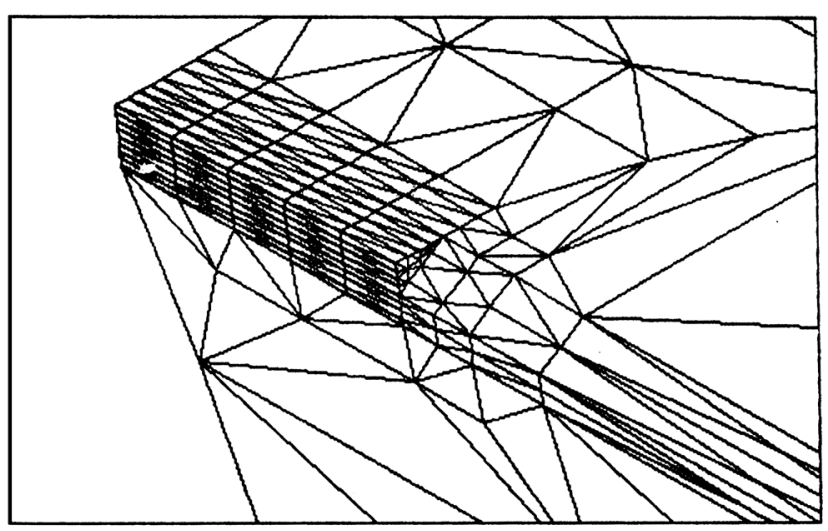

(b) Near the tool nose

Fig. 3 The boundary element mesh of the cutting insert

amount of mechanical load. This makes it necessary to develop a suitable strategy to distribute the cutting forces calculated by the models presented in section 2.

Considering the contact between the same materials and the high temperatures and pressures, a plastic contact was assumed on the flank side of the stagnation zone. Figure 5 shows the assumed distribution of the frictional and normal forces at the chip-tool and work-tool interfaces, along with a small wear land on the flank [18]. The rake face stress distribution is in accordance with the report by Barrow et al. [19]. $F_{1}, N_{1}$, and $F_{2}, N_{2}$ represent the net frictional and normal force pairs on the flank and rake face of the tool respectively. The magnitudes of $F_{1}, N_{1}, F_{2}$, and $N_{2}$ are evaluated in terms of $P_{z}$ and $P_{x}$, using the geometrical relationships.

\subsection{Evaluation of heat sources}

At higher speeds, considering the plasticity of the work material, the hardness of the stagnation zone,

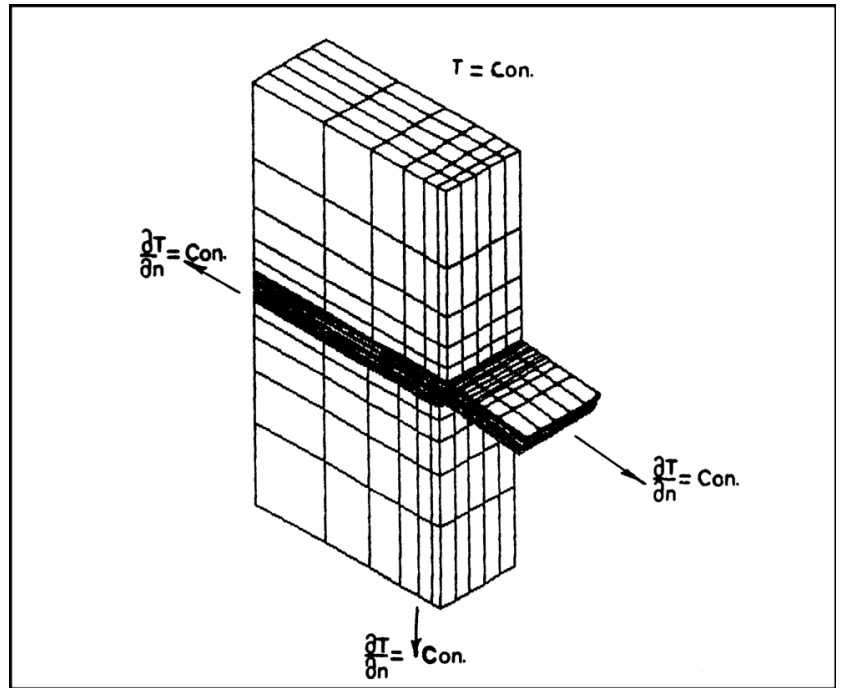

Fig. 4 The finite element mesh of the work material and the far boundary conditions

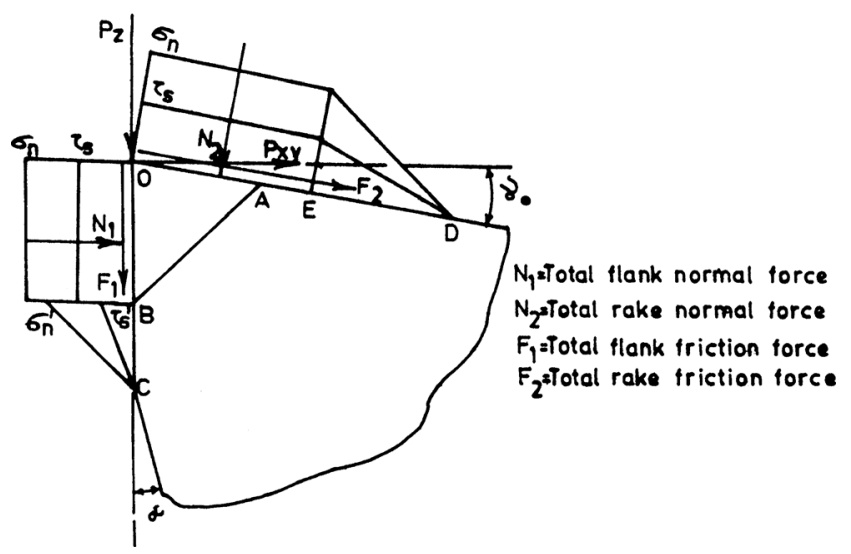

Fig. 5 Distribution of rake and flank face loads

and the overall stability of the cutting process, it is assumed that the stagnation zone takes a sharper appearance and plays the role of the cutting edge. It has also been observed previously [7] that there is little difference in the primary zone shear and the mechanism of flow of the chip over the rake face while cutting with sharp and bevelled tools, except for the presence of the stagnation zone and the consequent disturbance close to the nose, as is the case with a bevelled tool. Although these assumptions are in accordance with the findings of Movahhedy et al. [5], a single shear plane model is used in the present study for simplicity in all further calculations, as opposed to the shear zone reported by the earlier research.

Once a single shear plane model has been assumed, the evaluation of the heat sources, the dynamic heat balance, and the steady state temperature distribution are obtained using the mixed finite and boundary element method reported elsewhere by one of the 
present authors [11]. The method obtains the heat balance by treating the work-chip combination as one domain using the finite element method, and the cutting insert as the other domain using the boundary element method, and by iteratively adjusting the heat partition at different contact points until a steady state is reached. While employing the finite element solution in the work-chip domain, the whole length of the chip, starting from the shear plane in the downstream direction, is treated as one type of material and the rest of the domain as another type. This facilitated the specification of two mass flowrates. While the chip flow velocity, assumed to be uniform throughout, is specified as the mass flowrate in the chip region, the cutting velocity is specified as the mass flowrate in the bulk of the workpiece region. These conditions would make the solution procedure simulate the process more closely to the actual cutting conditions, at least as far as finding the heat balance at the chip-tool and work-tool interfaces is concerned.

Assuming that all the work done during the deformation process is converted into heat, the rate of heat generation at the primary deformation zone is calculated in each case as the difference between the total heat generated and the frictional heat at the rake face [16]. This heat source is assumed to be uniformly distributed and specified over a strip of elements considered parallel to the shear plane, the angle of which is established using the classical metal cutting principles, considering both that the presence of the stagnation zone plays the part of the missing tool nose and that conditions are close to those of conventional machining. The rake and flank face heat sources are evaluated and distributed at appropriate elements along the chip-tool and work-tool interfaces, using the load distribution patterns shown in Fig. 5. The actual heat partition between the two domains is obtained by beginning with an assumption of 70 per cent of rake face and flank face heat entering the work-chip domain and then iteratively adjusting this heat balance in a number of trials, until steady state conditions are achieved. The final heat fluxes into the tool obtained at different source points are used to obtain the thermal data reported here.

\section{RESULTS AND DISCUSSION}

As reported previously [11], the iterative solution, in all cases, converged on the final heat balance within three to four trials. The temperature distributions obtained with the final heat balance in the workchip and the tool domains of a tool of land width $0.40 \mathrm{~mm}$ and land angle $27^{\circ}$ are shown in Figs 6(a) and (b) respectively. Similar temperature distributions in the case of a sharp tool with the same process parameters are presented in Figs $7(\mathrm{a})$ and (b) for comparison.

Comparing the isothermal contours of Fig. 6(b) with those of Fig. 7(b) reveals certain interesting differences between the thermal behaviour of bevelled and sharp tools. First, the thermal gradients are very steep in the conventional tool, as may be observed from the sharp decline in the temperature values from the rake face. The bevelled tool has a more widespread temperature distribution. In a conventional tool, the majority of heat flow into the tool takes place from the rake face. The wear land heat source plays an insignificant role, as the fast-moving, newly generated work surface acts as a heat sink and takes away most of this heat. In a bevelled tool, the flank heat source is enhanced by the increased frictional forces owing to stagnation, and it finally causes a widespread distribution of the heat sources all around the tool nose region. The effect of the flank

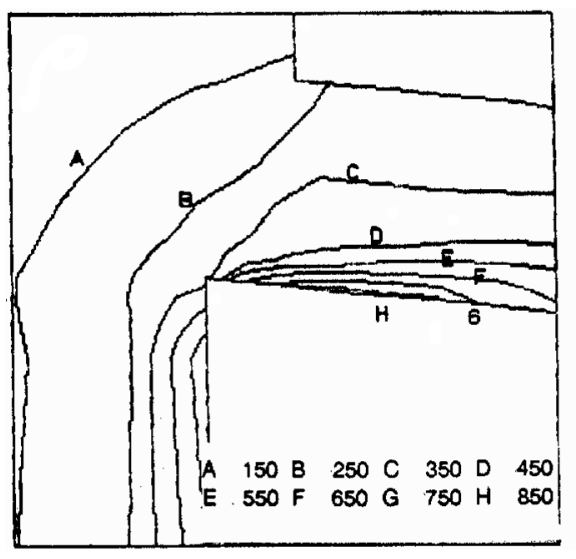

(a) In the work-chip domain

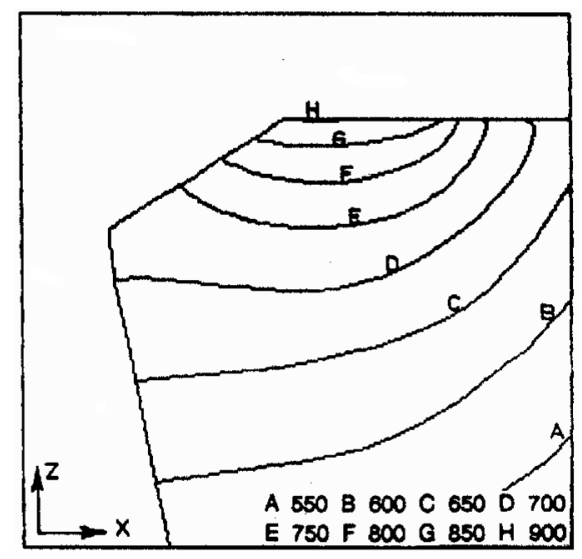

(b) In the tool domain

Fig. 6 Isothermal contours in the case of a tool of $b=0.40 \mathrm{~mm}$ and $\gamma_{1}=27^{\circ}$, while machining with $V_{\mathrm{c}}=180 \mathrm{~m} / \mathrm{min}, S_{0}=0.24 \mathrm{~mm} / \mathrm{rev}$ 


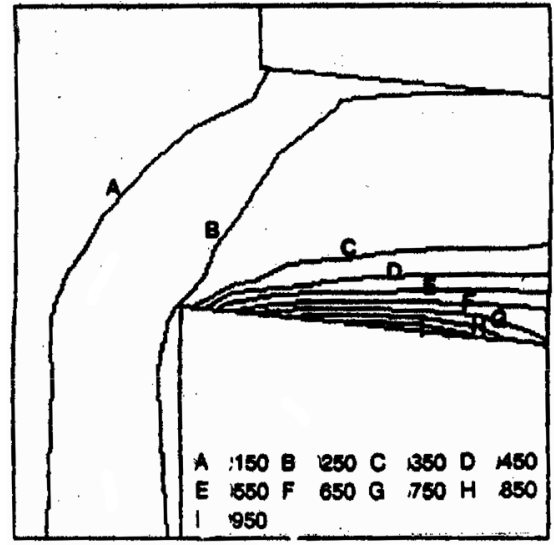

(a) In the work-chip domain

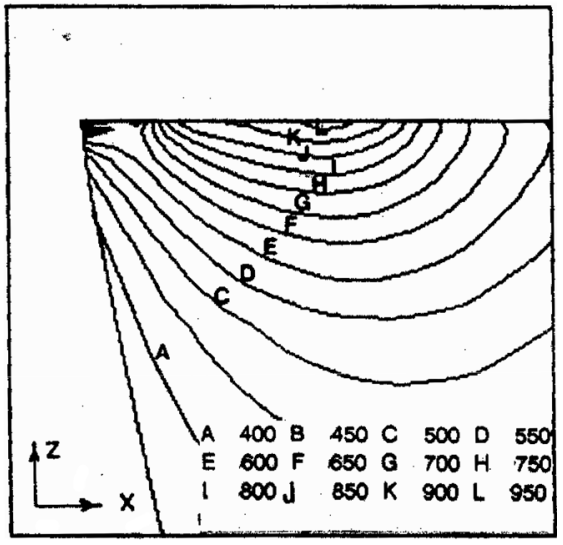

(b) In the tool domain

Fig. 7 Isothermal contours in the case of a conventional tool, while machining with $V_{\mathrm{c}}=180 \mathrm{~m} / \mathrm{min}$, $S_{0}=0.24 \mathrm{~mm} / \mathrm{rev}$

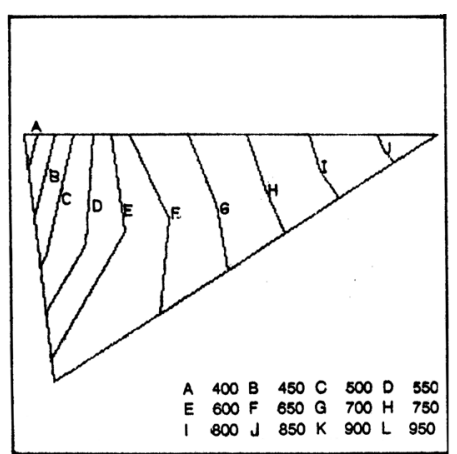

(a) Isothermal contours with $b=0.30 \mathrm{~mm}, \gamma_{1}=27^{0}$

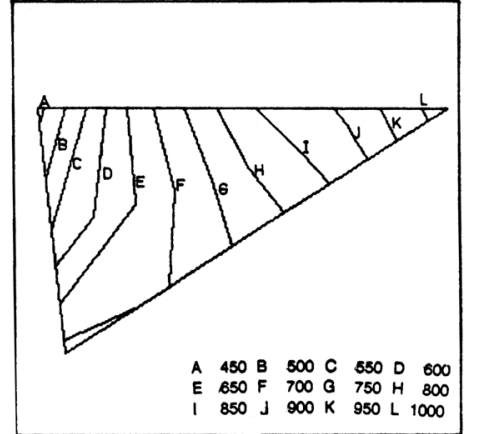

(b) Isothermal contours with $b=0.54 \mathrm{~mm}, \gamma_{1}=27^{0}$

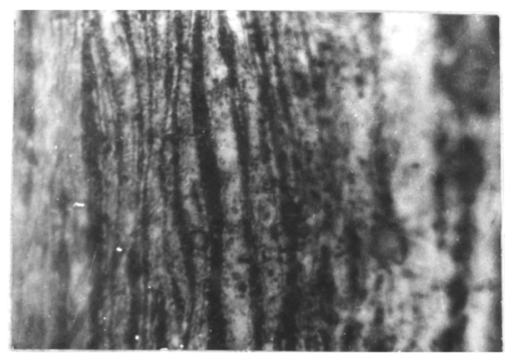

(c) Microstructure of the stagnation zone

Fig. 8 Thermal behaviour of the stagnation zone

heat source can be seen by comparing the peak flank temperature, which is a mere $300^{\circ} \mathrm{C}$ (isothermal contours B-C in Fig. 7(a)) in the case of the conventional tool, compared with a peak value as high as $650^{\circ} \mathrm{C}$ (isothermal contour F in Fig. 6(a)) in the case of the bevelled tool.

Second, a low-temperature zone exists very close to the tool nose in sharp cutting tools. As was also reported by Chao and Trigger [20], the freshly formed chip would be at a lower temperature at the entry on to the rake surface, compared with the temperature inside the tool, which is continuously heated up.
Owing to this process, heat actually flows from the cutting tool into the chip, in some portion of the chip-tool contact area, close to the cutting edge. As a result, in a small area near the cutting edge, the heat flow into the moving chip will be more than what is actually being generated owing to plastic deformation. Also, the fast-moving work surface continuously brushing past the wear land acts as an effective heat sink and actually removes some of the rake face heat entering the cutting tool domain. In a bevelled tool, all these transformations are more or less confined to that part of the tool occupied by the 


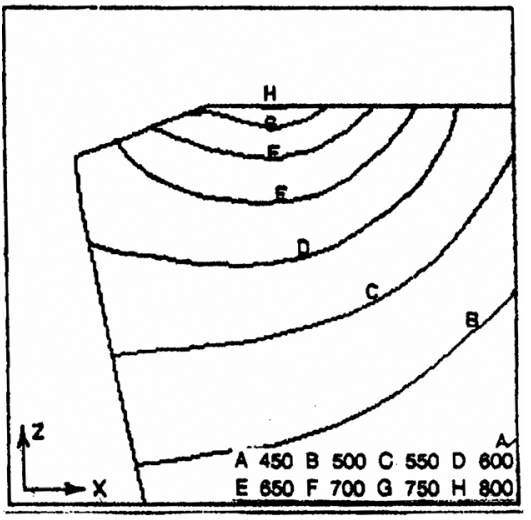

(a) $b=0.30 \mathrm{~mm}, \gamma_{1}=15^{\circ}$

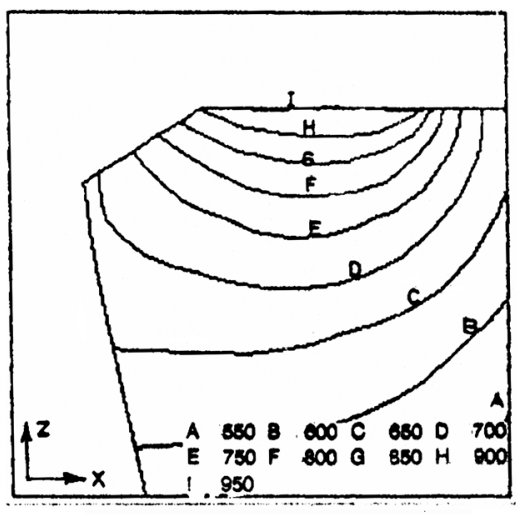

(b) $b=0.30 \mathrm{~mm}, \quad \gamma_{1}=27^{0}$

Fig. 9 Isothermal contours in the case of a tool of lower land width, while machining with $V_{\mathrm{c}}=180 \mathrm{~m} / \mathrm{min}, S_{0}=0.24 \mathrm{~mm} / \mathrm{rev}$

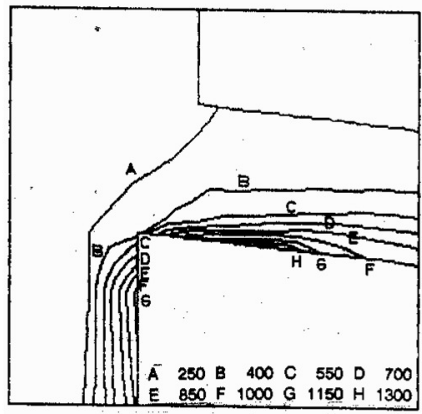

(a) In the work-chip domain

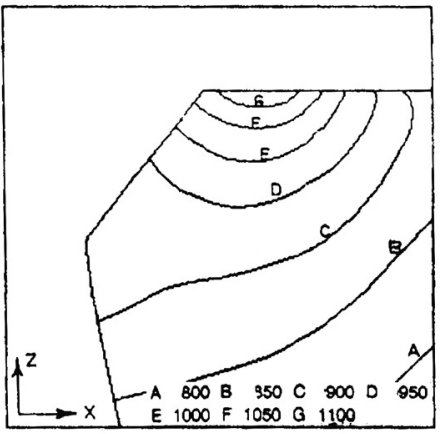

(b) In the tool domain

Fig. 10 Isothermal contours in the case of a tool of $b=0.54 \mathrm{~mm}$ and $\gamma_{1}=40^{\circ}$, while machining with $V_{\mathrm{c}}=180 \mathrm{~m} / \mathrm{min}, S_{0}=0.24 \mathrm{~mm} / \mathrm{rev}$

stagnated work material, and the actual tool experiences a more uniform temperature distribution all around the bevelled nose region.

Consequently, the portion of the tool occupied by the stagnant work material should have relatively low temperatures. This is clarified by the isothermal contours of Figs 8(a) and (b), presenting the temperature distribution in the stagnation zones of bevelled tools of two different geometries. Also, the photomicrograph of the stagnation zone of a deeply etched sample given in Fig. 8(c) shows the accumulation of pearlite, and squeezing-out of ferrite, indicating a lower temperature and a higher hardness for this region, as was also observed from microhardness measurements [7].

Figure 9(a) gives the temperature distribution in a bevelled tool of land width $0.3 \mathrm{~mm}$ and land angle $15^{\circ}$. The peak temperature is lower compared with a tool of higher land width and land angle. The location of the peak temperature is also shifted on to the rake surface, beyond the negative land, as depicted by the location of the isothermal contour $\mathrm{H}$. The shifting-away of the location of the peak temperature is even more pronounced (as shown by the location of the isothermal contour I in Fig. 9(b)) in the case of a tool with the same land width but a higher land angle, which results from a wider chip-tool contact length. On the other hand, when both land width and land angle are reasonably high, the location of the peak temperature was found to move closer to the cutting edge, as is the case with the result shown in Fig. 6(b), for a tool of land width $0.40 \mathrm{~mm}$ and land angle $27^{\circ}$. At sufficiently high land width and land angle, the chip-tool contact length decreases owing to the controlled contact cutting effect, and this results in a concentration of the rake face heat sources closer to the cutting edge. The temperature distributions in the work-chip and tool domains are shown in Fig. 10, for the case of a bevelled tool of land width $0.54 \mathrm{~mm}$ and land angle $40^{\circ}$, and these demonstrate the profound influence of the wider flank contact of a larger stagnation zone in raising the temperature values at the principal flank.

The peak rake face temperatures obtained while analysing tools of different geometries are plotted against land width and land angle as shown in 


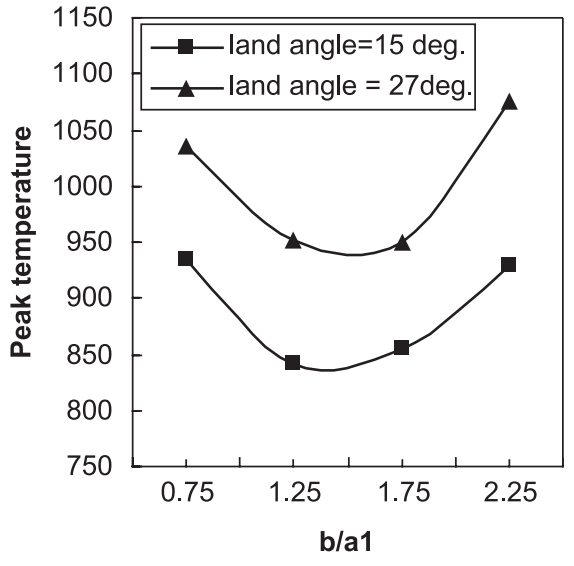

(a) With land width

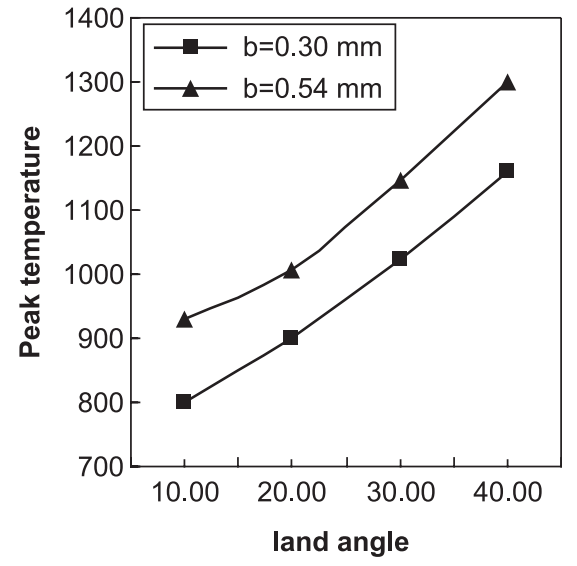

(b) With land angle

Fig. 11 Variation of the peak temperature with land width and land angle

Figs 11(a) and (b). The effect of the land width has a direct bearing on the magnitude of the uncut chip thickness (shown as $a_{1}$ in Fig. 1), which in turn depends on the value of feed. The ratio of land width to uncut chip thickness, $b / a_{1}$ is used as the parameter on the $X$-axis in Fig. 11(a) to depict the combined influence on the peak temperature. For a given feed, it can be seen that the value of the peak temperature decreases to some extent, attains a minimum value, and then increases with increase in land width. This initial reduction in the peak temperature with an increase in the land width is due to the gradual increase in the flank face length (OB in Fig. 5) of the stagnation zone and the consequent apportionment of the cutting forces on that side. However, with further increase in $b$, the cutting forces, and in particular the friction forces, increase, thereby resulting in a general rise in the temperature. On the other hand, the almost linear rise in the peak temperature as seen in Fig. 11(b) is due to the steep rise in the frictional forces with land angle.

\section{CONCLUSIONS}

The presence of the stagnated work material plays a significant role in the thermal behaviour of bevelled tools. The stagnation zone plays a sacrificial role in cushioning the tool from the chip load, as well as removing the heat sources from the immediate vicinity of the tool nose. The benefits expected in terms of reduced chances of edge chipping and cracking, if any, must be due to the more uniform temperature distribution resulting from the enhanced flank heat source. The peak value of the chip-tool interface temperature varies with the land geometry and becomes a minimum when the land width and land angle are around $0.35 \mathrm{~mm}$ and $15^{\circ}$ respectively.

\section{REFERENCES}

1 Chao, B. T. and Trigger, K. J. Controlled contact cutting tools. Trans. ASME, J. Engng for Industry, 1959, 81, 139.

2 Bhattacharya, A. and Ghosh, R. K. Mechanics of chip formation of controlled contact cutting tools. J. Inst. India, 1961, 42(3, part ME2), 80.

3 Trigger, K. J. and Bhattacharya, A. Cutting performance of controlled contact cutting tools. J. Inst. Engrs India, 1962, 43(3, part ME2), 142.

4 Hirao, M., Tlusty, J., Sowerby, R., and Chandra, G. Chip formation with chamfered tools. Trans. ASME, J. Engng for Industry, 1982, 104, 339.

5 Movahhedy, M. R., Atlantis, Y., and Gadala, M. S. Numerical analysis of metal cutting with chamfered and blunt tools. Trans. ASME, J. Mfg Sci. Engng, 2002, 124, 178.

6 Sikdar, C., Babu, S. S., Chattopadhyay, A. B. and Venkatesh, V. C. Effect of beveling of carbide turning inserts on chip formation and cutting forces. J. Mater. Processing Technol., 1991, 28, 15.

7 Babu, S. S., Chakraborthy, A. K., and Chattopadhyay, A. B. Microscopic study on chips formed by sharp and beveled turning carbide inserts. J. Mater. Processing Technol., 1993, 37, 781.

8 Shaw, M. C. Fracture of metal cutting tools. Ann. CIRP, 1979, 28(1), 12.

9 Kaldor, S. and Venuvinod, P. K. Macro-level optimization of cutting tool geometry. Trans. ASME, J. Mfg Sci. Engng, 1997, 119, 1.

10 Ostafiev, V. A. and Noschenko, A. N. Thermo strength of carbide tools. Ann. CIRP, 1989, 38, 65.

11 Singamneni, S. B. A mixed solution for the three dimensional temperature distributions in turning inserts using finite and boundary element techniques. J. Mater. Processing Technol., 2005, 166, 98-106.

12 Box, G. E. P. and Wilson, K. B. On the experimental attainment of optimum conditions. J. Ro. Statist. Soc., Ser. B (Methodological), 1951, 13(1), 1-45.

13 Box, G. E. P. and Hunter, J. S. Multi-factor experimental designs for exploring response surfaces. Ann. Math. Statists, 1957, 28(1), 195-241. 
14 Cochran, W. G. and Cox, M. Experimental design, 1992 (Wiley, New York).

15 Usui, E., Kukuchi, K., and Hoshi, K. Theory of plasticity applied to machining with cut-away tools. Trans. ASME, J. Engng for Industry, 1964, 86, 95.

16 Shaw, M. C. Metal cutting principles, 1984 (Clarendon Press, Oxford).

17 Gupta, O. P. and Babu, S. S. Error analysis in applying a boundary element method for three-dimensional steady state potential problems. Computers Structs, 1996, 58(2), 289.
18 Muraka, P. D., Barrow, G., and Hinduja, S. Influence of the process variables on the temperature distribution in orthogonal machining using the finite element method. Int. J. Machine Tool Des. Res., 1979, 21, 445.

19 Barrow, G., Graham, W., Kurimoto, T., and Leong, Y. F. Determination of rake face stress distribution in orthogonal machining. Int. J. Machine Tool Des. Res., 1982, 22, 75.

20 Chao, B. T. and Trigger, K. J. Temperature distribution at the chip-tool interface in metal cutting. Trans. ASME, 1955, 77, 1331. 